\title{
Plasma decontamination of sealed packages
}

\author{
H.E. Potts ${ }^{1}$, D.A. Diver ${ }^{1}$, P.C. Everest ${ }^{2}$, R.D. O'Connor ${ }^{3}$ \\ ${ }^{1}$ SUPA, School of Physics and Astronomy, Kelvin Building, University of Glasgow, Glasgow G12 8QQ, UK \\ ${ }^{2}$ School of Veterinary Medicine, University of Glasgow, Glasgow, G12 8QQ, UK \\ ${ }^{3}$ Microsearch Laboratories Ltd, Unit 11, Moderna Business Park, Mytholmroyd, Halifax, West Yorkshire, HX7
}

$5 Q Q, U K$

\begin{abstract}
We have developed an unusual plasma source that allows the generation of plasma exclusively within a sealed container or bag, from an entirely external electrode system. This device is unique in that it can be applied to standard sealed packaging and does not subject the package contents to any significant electric fields. This system can be used to modify the atmosphere inside the package by generating active species such as free radicals and ozone from the gas within it. This allows, for example, sterilisation or decontamination of the contents of a presealed container without the risks associated with handling ozone in open atmosphere. We present results showing the efficacy of this system in reducing the contamination of foodstuffs with pathogens such as Campylobacter and E.coli.
\end{abstract}

\section{Introduction}

Ozone $\left(\mathrm{O}_{3}\right)$ is a powerful germicide $[1,2]$, formed from the transformation of molecular oxygen $\left(\mathrm{O}_{2}\right)$ by the action of plasma discharge. We have developed a novel plasma source with multiple applications, with the key feature that it can produce a plasma (and hence ozone) wholly inside a sealed container from an electrode system entirely outside the container.

In many ways ozone is the ideal sterilising agent: it can be created from oxygen in air, and any residual ozone decays spontaneously back to oxygen within a timescale of minutes to a few hours, leaving no toxic compounds behind. Ozone is also a very rapid sterilizing agent: it has been found to work hundreds to thousands of times faster than chlorine in a disinfectant role [1]. Ozone is particularly effective against spores, moulds, viruses and bacteria, and has long been used extensively for sterilizing water, and to suppress mould growth and bacterial populations in stored foodstuffs: for example, surface microorganisms on the surface of refrigerated meat under storage are destroyed by exposure to ozone [4] with minimal effect on the quality and nutrient content with storage lifetime increased by up to $40 \%$. Recently there has been renewed interest in using ozone for destroying pathogens in food products, as part of the production and preservation process $[2,5,6]$. One driver for this is the phasing out of chlorine washes in meat production due to health concerns about compounds formed when chlorine reacts with food.

The main obstacle to widespread use of ozone in industrial manufacturing is the hazards associated with creating and handling it. The fact that ozone spontaneously decomposes at room temperature means that it is nearly impossible to store and must be created at the point of use, a process requiring high voltages, typically via a corona discharge. It is also highly toxic, with a maximum user exposure of only $0.1 \mathrm{ppm}$, making it difficult to safely insert into packages prior to sealing.

It is this key element that we believe is addressed in this application. Our plasma technology can be used to sterilise pre-packaged items without opening or damaging the package, by causing a plasma discharge to be initiated inside the package while in contact with the plasma source. Packaged goods are brought to very close contact with the outer surface of the device, so that the bag effectively becomes another dielectric layer on its outer electrode. A pulse of power initiates a transient low-temperature plasma inside the sealed package, resulting in the generation of ozone within the package. There is no significant thermal load on either the packaging itself or its contents, and the plasma does not directly interact with the bag contents. The ozone then permeates the entire package interior, reacting with any surfaces encountered and destroying bacterial and fungal deposits. 


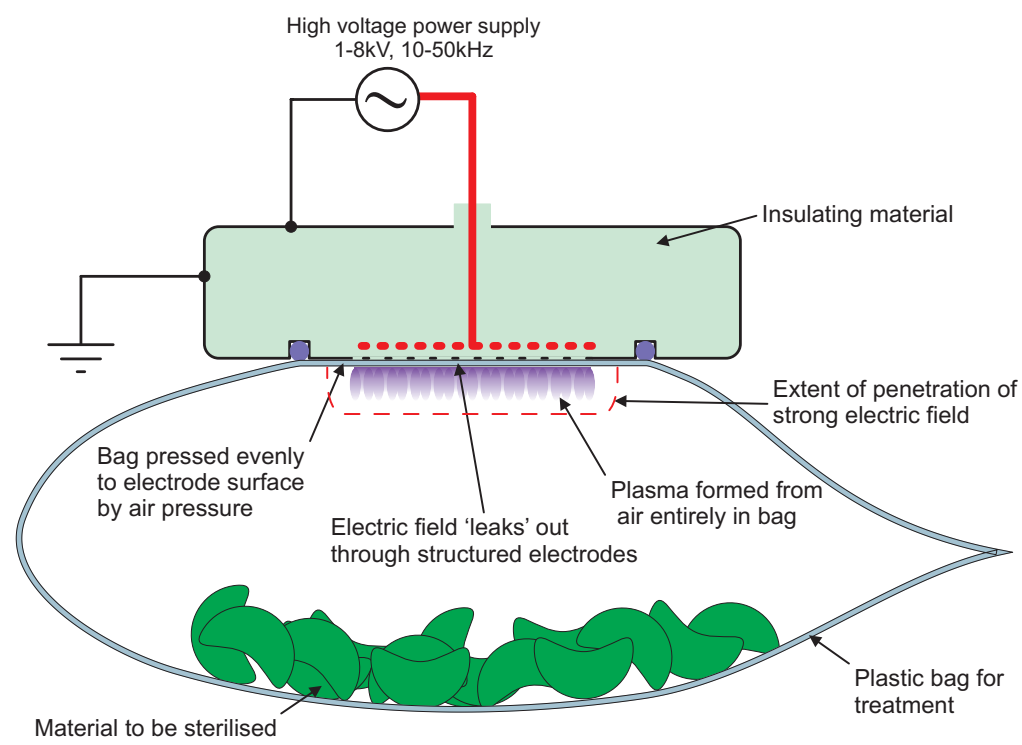

Fig. 1: Diagram showing the geometry of the plasma system

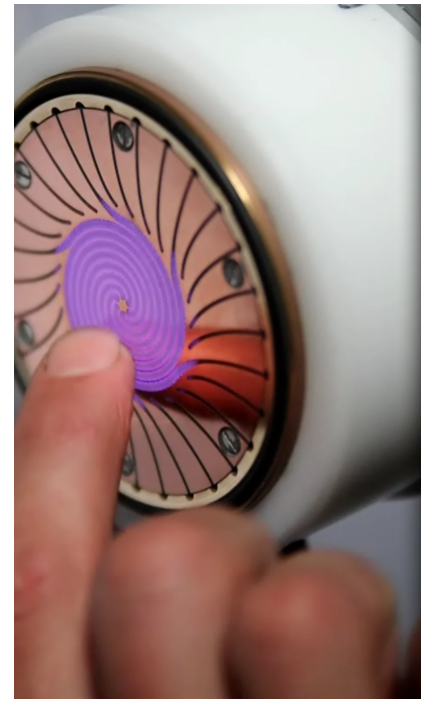

Fig. 2: A demonstration of the author touching the surface of the discharge head while it is energised

\section{Apparatus}

The plasma source uses two structured conducting electrodes, as shown in figure 1. The inner conductor is powered and is entirely encapsulated in insulating material. A high-voltage AC power supply is connected to this electrode (1-8 $\mathrm{kV}, 10-50 \mathrm{kHz})$. The outer electrode is grounded, but not solid: it is patterned in such way that the electric field from the inner electrode is not perfectly screened, producing an arrangement of localised strong electric field gradient on top of the device itself. An important feature of this geometry is that the electric field is effectively confined to the volume just in front of the electrode. This means that the contents of the container are not subjected to any significant electric field, and therefore are outside the plasma production region. This means that the system can produce accurately calibrated quantities of ozone within the container independent of the bag contents and disposition. All the outer surfaces are either earthed or constructed of insulating material, making the device intrinsically electrically safe for the user even under wet conditions. This is demonstrated in figure 2, where a user can be seen touching the energised electrode system. The plasma itself is formed in those regions where the strong electric field is present - that is, where the field 'leaks' through the upper conducting plate. With the sealed bag firmly attached to the upper surface via vacuum suction, the bag material effectively becomes an insulating layer on the outer electrode; this doesn't significantly change the electric field arrangement, and so the plasma is struck inside the bag. If the bag were not present, the plasma would be formed on the outer surface of the device, as in figure 2. The plasma so produced is uniform and diffuses over the entire area of the upper plate. There are no significant 'hot spots', and the thermal load is minimal; this allows the system to work with even thermally sensitive plastic films such as polythene.

Some biological contaminants develop resistance to ozone treatment by forming clumps, leading to the detritus of destroyed material forming a layer which protects untreated contaminants. Ul- 


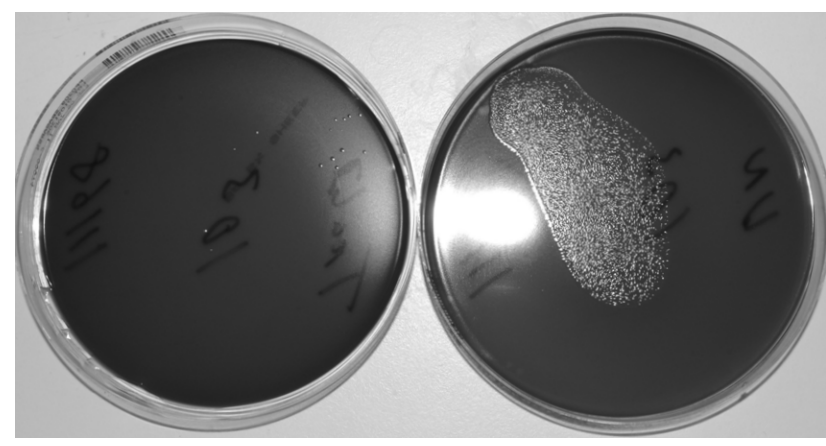

Fig. 3: The effect of $1 \mathrm{mg}$ of ozone on $10^{3} \mathrm{CFU}$ of Campylobacter jejuni incubated on blood agar. left treated with ozone, right untreated

\begin{tabular}{|c|c|c|c|}
\hline Inoculation & Untreated & Treated & log redn \\
\hline $10^{3}$ & 1430 & 10.3 & 2.1 \\
$10^{5}$ & 110,000 & 80 & 3.1 \\
$10^{7}$ & $10^{7}$ (est.) & 400 & 4.4 \\
\hline
\end{tabular}

Table 1: Results in counted cfu (colony forming units) for treated and untreated agar plates inoculated with Campylobacter jejuni

trasound bursts have been demonstrably effective in combination with ozone treatment (see for example $[1,7,8]$ ) by causing break-up of clumping or direct disruption of the cell membranes. Since our device can be modulated at audio frequencies and above, it is possible to induce ultrasound and ozone simultaneously using the same device, making it much more potent than previous technologies. A patent application (GB0919274.1) was submitted in 2009 covering the device described above.

\section{Sterilisation Efficacy}

In order to evaluate the efficacy of the system in inactivating pathogens microbiological experiments were carried out first on plated Campylobacter and then of commercially produced chicken with natural flora.

\subsection{Plated Campylobacter}

The efficacy of the plasma ozone system was demonstrated in the context of inactivating Campylobacter on petri dishes. Samples of Campylobacter jejuni were plated onto blood agar at three different concentrations: $10^{3}, 10^{5}$ and $10^{7}$ colony forming units (cfu). Half of the sample dishes were kept as control samples, the other half were sealed temporarily into polythene bags and treated for 30 s with the plasma ozone system, exposing the inoculum to approximately $1 \mathrm{mg}$ of ozone. The treated dishes were then removed from the bags after 30 mins, and stored under identical conditions to the control samples. The samples were then incubated for 24 hours and the viable colonies counted. Campylobacter jejuni was chosen for these experiments as it is a particularly nasty bacterial contamination of raw poultry, accounting for one third of all UK food poisoning cases and is proving problematic in the UK retail food industry.

The results were excellent, and are summarised in table 1: in the lowest inoculum case, the untreated sample showed 1430 cfu one day after preparation, whereas the treated sample showed only 10; the plasma treatment had reduced the bacterial load by a factor 100, essentially eliminating it. The medium and high inoculums showed even more dramatic reductions: the control vs treated samples for the $10^{5}$ case were 110,000 cfu and 80 cfu respectively, and for the $10^{7}$ case, the control sample had too many cfu to count, whereas the treated sample had only 400 . These first tests showed that the plasma system could be a powerful tool in the eradication of bacteria in packaged goods under ideal test conditions.

\subsection{Retail poultry}

To test the system in a more realistic context, retail pre-packaged poultry portions were treated in their sealed tray packs in their original modified atmosphere of $80 \%$ oxygen, $20 \%$ carbon dioxide, and these were tested by an independent microbiological testing agency (Microsearch) against control samples from the same retail supplier. Table 2 summarises the results of testing for Total Viable Count (TVC) (the total number of microorganisms that are active), Enterobacteriaceae (Enterobact., a large family of general pathogens such as Salmonella), Escherichia coli (E.coli, the bacterium often found in the lower intestine of mammals), Pseudomonas (Pseud, a general family of bacteria) and Campylobacter jejuni (often found in poultry as a surface contaminant). Two different classes of poultry were treated: chicken breast with skins on and skinless breast. After ozone treatment the sealed packs of poultry were stored for 24 hours and then the microbiological analysis performed. The analysis was performed 


\begin{tabular}{|l|l|c|c|c|c|c|}
\hline & $\begin{array}{l}\text { Ozone } \\
(\mathrm{mg})\end{array}$ & $\begin{array}{c}\text { TVC } \\
(\mathrm{cfu} / \mathrm{g})\end{array}$ & $\begin{array}{c}\text { Enterobact. } \\
(\mathrm{cfu} / \mathrm{g})\end{array}$ & $\begin{array}{c}\text { Pseudomonas } \\
(\mathrm{cfu} / \mathrm{g})\end{array}$ & $\begin{array}{c}\text { E.coli } \\
(\mathrm{cfu} / \mathrm{g})\end{array}$ & $\begin{array}{c}\text { Campylobacter } \\
(\mathrm{cfu} / \mathrm{g})\end{array}$ \\
\hline skin-on breast & $0($ control$)$ & $4.6 \times 10^{6}$ & 4700 & $8.1 \times 10^{5}$ & 670 & 190 \\
\cline { 2 - 7 } & $1.2 \mathrm{mg}$ count & $3.1 \times 10^{4}$ & 1100 & $2.3 \times 10^{4}$ & 170 & 65 \\
& $1.2 \mathrm{mg} \log$ kill & $\mathbf{2 . 2}$ & $\mathbf{0 . 6}$ & $\mathbf{1 . 5}$ & $\mathbf{0 . 6}$ & $\mathbf{0 . 5}$ \\
\cline { 2 - 7 } & $3.0 \mathrm{mg}$ count & $2.4 \times 10^{4}$ & 89 & $8.7 \times 10^{3}$ & 82 & 12 \\
& $3.0 \mathrm{mg} \log$ kill & $\mathbf{2 . 3}$ & $\mathbf{1 . 7}$ & $\mathbf{2 . 0}$ & $\mathbf{0 . 9}$ & $\mathbf{1 . 2}$ \\
\hline \hline skin-off breast & 0 (control) & $5.3 \times 10^{6}$ & 8200 & $7.3 \times 10^{5}$ & 930 & 310 \\
\cline { 2 - 7 } & $1.2 \mathrm{mg}$ count & $1.3 \times 10^{4}$ & 130 & $9.2 \times 10^{3}$ & 40 & 30 \\
& $1.2 \mathrm{mg} \log$ kill & $\mathbf{2 . 6}$ & $\mathbf{1 . 8}$ & $\mathbf{1 . 9}$ & $\mathbf{1 . 4}$ & $\mathbf{1 . 0}$ \\
\cline { 2 - 7 } & $3.0 \mathrm{mg}$ count & 250 & 12 & 280 & 0 & 0 \\
& $3.0 \mathrm{mg} \log$ kill & $\mathbf{4 . 3}$ & $\mathbf{2 . 8}$ & $\mathbf{3 . 4}$ & $>\mathbf{3 . 0}$ & $>\mathbf{2 . 5}$ \\
\hline \hline
\end{tabular}

Table 2: Microbiological enumeration results for treated and untreated retail packed chicken

on skin tissue or $2 \mathrm{~mm}$ surface sections in the case of skinless product from surfaces exposed to the ozone. For each chicken type the experiments were repeated six times, and each experiment had two separate analyses; the results in table 2 are the average of all these.

The results are very encouraging, particularly for the skin-off breast, where a complete kill was seen for E.coli and Campylobacter in the $3 \mathrm{mg}$ case, and substantial reductions for all other organisms, including a $4.3 \mathrm{log}$ reduction in the total viable count (a $99.995 \%$ reduction).

The conclusion from these studies is that this system has great promise for large-scale food treatment, displacing traditional chemical based disinfection methods.

\section{Acknowledgements}

HEP and DAD are grateful for funding from STFC Follow-on Fund (ST/H00274X/1), EPSRC KTA (KTA EP/H500138/1); HEP acknowledges Advanced Fellowship funding from SUPA (Scottish Universities Physics Alliance). Support from the University of Glasgow Research \& Enterprise staff (particularly $M$ Anderson) in forming the spin-out company Anacail Ltd is gratefully acknowledged. Finally, we are very grateful to our colleagues in the University of Strathclyde, particularly Alan Phelps and Robbie Stewart, for their encouragement and assistance in our early experiments.

\section{References}

[1] Horvath M, Bilitzky L \& Huttner R J: 'Ozone', Topics in inorganic and general Chemistry Vol 20, Elsevier, Oxford, 1986 ISBN 0-444-99625-7

[2] Mahapatra A K, Muthukumarappan K \& Julson J: 2005 'Applications of Ozone, Bateriocins and Irradiation in Food Processing: a Review', Critical Rev. Food Science and Nutrition, 45 447461

[3] Fetner R H \& Ingols R S: 1956, 'A comparison of the bactericidal activity of ozone and chlorine against Escherichia coli at 1-degree', J. Gen. Microbiol. 15, 381

[4] Kolodyaznaya, V S \& Suponina, T A: 1975 'Storage of foods using ozone', Kholohilnaya Tekhnika 6, 39-41 and Application Data Sheet $003.01(1 / 2 / 95)$ from NuTek International, Inc. Florida.

[5] Townley, P: 2008 'Sanitising systems for the food processing industry', Food Science Central online feature (http://www.foodsciencecentral.com/fsc/ixid12558)

[6] Hassenberg K, Idler C, Molloy E, Geyer M, Plochl M \& Barnes J: 2007, 'Use of ozone in a lettuce-washing process: an industrial trial', J Sci Food Agric 87 914-919

[7] Krasnyj W, Klosovskij A V, Panasko T A, Shvets O M, Semenova O T, Taran V S \& Tereshin V I: 2008, 'Sterilization of microorganisms by ozone and ultrasound', AIP Conference Proceedings 993 387-390

[8] Barbosa-Canovas G V \& Bermudez-Aguirre D: 2008 Food Sci. Tech. Intl. 14, 0403-409 